\title{
Speed Control of De Motor Using Fuzzy Logic Technique
}

\author{
${ }^{1}$ J. N. Rai, ${ }^{2}$ Mayank Singhal, ${ }^{3}$ MayankNandwani \\ ${ }^{1,2,3}$ Department of Electrical Engineering, Delhi Technological University
}

\begin{abstract}
This project uses FUZZY LOGIC TECHNIQUE in estimating speed and controlling it for DC motor. The rotor speed of the dc motor can be made to follow an arbitrarily selected trajectory. The purpose is to achieve accurate trajectory control of the speed of DC Motor, especially when the motor and load parameters are unknown. Such a control scheme gives very accurate and precise result in very short time. The fuzzy logic controller employs if-else form programming of the various conditions to control the motor speed.
\end{abstract}

\section{Introduction}

Direct current (DC) motors have been widely used in many industrial applications such as electric vehicles, steel rolling mills, electric cranes, and robotic manipulators due to precise, wide, simple and continuous control characteristics. The development of high performance motor drives is very important in industrial as well as other purpose applications. Generally, a high performance motor drive system must have good dynamic speed command tracking and load regulating response. DC drives, because of their simplicity, ease of application, reliability and favourablecost have long been a backbone of industrial applications. DC drives are less complex with a single power conversion from AC to DC. DC drives are normally less expensive for most horsepower ratings. DC motors have a long tradition of use as adjustable speed machines and a wide range of options have evolved for this purpose. In these applications, the motor should be precisely controlled to give the desired performance.

Traditionally rheostatic armature control method was widely used for the speed control of low power dc motors. However the controllability, cheapness, higher efficiency, and higher current carrying capabilities of static power converters brought a major change in the performance of electrical drives.

Many varieties of control schemes such as $\mathrm{P}$, proportional integral (PI), proportional derivation integral (PID), adaptive, and fuzzy logic controller (FLCs), have been developed for speed control of dc motors. As PID controllers require exact mathematical modelling, the performance of the system is questionable if there is parameter variation. In recent years neural network controllers (NNC) were effectively introduced to improve the performance of nonlinear systems. The proposed controller systems consist of multi-input fuzzy logic controller (FLC) and multi-input integrated fuzzy logic controller (IFLC) for the speed control.

\author{
Motor Control Constraints \\ 1. Non linearity in de motor \\ 2. Variable and unpredictable inputs \\ 3. Noise propagation along a series of unit processes \\ 4. Unknown parameters \\ 5. Changes in load dynamics
}

Major problems in applying a conventional control algorithm in a speed controller are the effects of non-linearity in a DC motor. The non-linear characteristics of a DC motor such as saturation and friction could degrade the performance of conventional controllers. Many advance model-based control methods such as variable-structure control and model reference adoptive control have been developed to reduce these effects. However, the performance of these methods depends on the accuracy of system models and parameters. Generally, an accurate non-linear model of an actual DC motor is difficult to find, and parameter values obtained from system identification may be only approximate values. Even the PID controllers require exact mathematical modelling.
Advantage of using fuzzy technique
1. Inherent approximation capability
2. High degree of tolerance
3. Smooth operation
4. Reduce the effect of Non-linearity Fast adaptation
5. Learning ability 
Emerging intelligent techniques have been developed and extensively used to improve or to replace conventional control technique because these techniques do not require a precise model. One of intelligent technique, fuzzy logic by Zadeh is applied for controller design in many applications. A fuzzy logic controller (FLC) was proved analytically to be equivalent to a non-linear PI controller when a non-linear defuzzification method is used. Also, the result from the comparisons of conventional and fuzzy logic control techniques in the form of a FLC and fuzzy compensator showed fuzzy logic can reduce the effects of non-linearity in a DC motor and improve the performance of a controller.

\section{Speed control techniques in de motor}

1. Varying the armature voltage in the constant torque region.

2. In the constant power region, field flux should be reduced to achieve speed above the rated speed.

\section{Methods of speed control}

1. Traditionally rheostat armature control method was used for low power dc motors.

2. Use of conventional PID controllers.

3. Neural network controllers (NNC).

4. Constant power field weakening controller based on load-adaptive multi-input multi-output linearization technique (in high speed regimes).

5. A single phase uniform PWM ac-dc buck-boost converter with only one switching device used for armature voltage control.

6. Use of NARMA-L2 (Non-linear Auto-regressive Moving Average) controller in the constant torque region.

\section{Seprately Excited Dc Motor}

The field windings are used to excite the field flux

Armature current is supplied to the rotor via brush and commutator for the mechanical wok

Interaction of field flux and armature current in the rotor produces torque

\section{Operation}

When a separately excited motor is excited by a field current of $i_{f}$ and an armature current of $i_{a}$ flows in the circuit, the motor develops a back emf and a torque to balance the load torque at a particular speed.

The if is the independent of the $\mathrm{i}_{\mathrm{a}}$. Each winding are supplied separately. Any change in the armature current has no effect on the field current.

The $\mathrm{i}_{\mathrm{f}}$ is normally much less than the $\mathrm{i}_{\mathrm{a}}$.

Field and Armature Equation

Instantaneous field current:

$\mathrm{V}_{\mathrm{f}}=\mathrm{i}_{\mathrm{f}}+\mathrm{L}_{\mathrm{f}} *(\mathrm{di} / \mathrm{dt})$

Where $\mathrm{R}_{\mathrm{f}}$ and $\mathrm{L}_{\mathrm{f}}$ are the field resistance and inductor, respectively.

Instantaneous armature current:

$\mathrm{V}_{\mathrm{a}}=\mathrm{R}_{\mathrm{a}} \mathrm{i}_{\mathrm{a}}+\mathrm{L}_{\mathrm{a}} *\left(\mathrm{di} \mathrm{a}_{\mathrm{a}} / \mathrm{dt}\right)+\mathrm{e}_{\mathrm{g}}$

where $R_{a}$ and $L_{a}$ are the armature resistance and inductor, respectively.

The motor back emf, which is also known as speed voltage, is expressed as:

$\mathrm{e}_{\mathrm{b}}=\mathrm{K}_{\mathrm{v}} \omega \mathrm{i}_{\mathrm{f}}$

$\mathrm{K}_{\mathrm{v}}$ is the motor voltage constant (in V/A-rad/sec) and $\omega$ is the motor speed (in rad/sec)

Torque Equation and Analysis inertia, i.e.:

For normal operation, the developed torque must be equal to the load torque plus the friction and

$\mathrm{T}_{\mathrm{d}}=\mathrm{J}^{*}(\mathrm{~d} \omega / \mathrm{dt})+\mathrm{B} \omega+\mathrm{T}_{1}$

Where,

B: Viscous friction constant (N.m/rad/sec)

$\mathrm{T}_{1}$ : Load Torque (N.m)

J: Inertia of the motor (Kg.m2) 
The torque developed by the motor is:

$\mathrm{T}_{\mathrm{d}}=\mathrm{K}_{\mathrm{t}} \mathrm{i}_{\mathrm{f}} \mathrm{i}_{\mathrm{a}}$

Where $\left(\mathrm{K}_{\mathrm{t}}=\mathrm{K}_{\mathrm{v}}\right)$ is torque constant in V/A-rad/sec.

Sometimes it is written as:

$\mathrm{T}_{\mathrm{d}}=\mathrm{K}_{\mathrm{t}} \square \mathrm{i}_{\mathrm{a}}$

From Newton's Second Law, Torsional-Mechanical equation is given as $\mathrm{d} \omega_{\mathrm{r}} / \mathrm{dt}=(1 / \mathrm{J})\left(\mathrm{T}_{\mathrm{e}}-\mathrm{T}_{\text {viscous }}-\mathrm{T}_{\mathrm{l}}\right)=(1 / \mathrm{J})\left(\mathrm{L}_{\mathrm{af}} \mathrm{i}_{\mathrm{a}} \mathrm{i}_{\mathrm{f}}-\mathrm{B}_{\mathrm{m}}-\mathrm{T}_{\mathrm{l}}\right)$

The nonlinear differential equation for separately excited DC motor which is found using Kirchhoff's Voltage Law

$\mathrm{di}_{\mathrm{a}} / \mathrm{dt}=-\left(\mathrm{r}_{\mathrm{a}} / \mathrm{L}_{\mathrm{a}}\right) \mathrm{i}_{\mathrm{a}}-\left(\mathrm{L}_{\mathrm{a} f} / \mathrm{L}_{\mathrm{a}}\right) \mathrm{i}_{\mathrm{f}} \omega_{\mathrm{r}}-\left(1 / \mathrm{L}_{\mathrm{a}}\right) \mathrm{u}_{\mathrm{a}}$

$\mathrm{di}_{\mathrm{f}} / \mathrm{dt}=-\left(\mathrm{r}_{\mathrm{f}} / \mathrm{L}_{\mathrm{f}}\right) \mathrm{i}_{\mathrm{f}}+\left(1 / \mathrm{L}_{\mathrm{f}}\right) \mathrm{u}_{\mathrm{f}}$

$\mathrm{d} \omega_{\mathrm{r}} / \mathrm{dt}=\left(\mathrm{L}_{\mathrm{af}} / \mathrm{J}\right) \mathrm{i}_{\mathrm{a}} \mathrm{i}_{\mathrm{f}}-\left(\mathrm{B}_{\mathrm{m}} / \mathrm{J}\right) \omega_{\mathrm{r}}-\left(\mathrm{T}_{\mathrm{l}} / \mathrm{J}\right)$

Using Newton's Second Law

$\mathrm{d} \omega_{\mathrm{r}} / \mathrm{dt}=(1 / \mathrm{J})\left(\mathrm{T}_{\mathrm{e}}-\mathrm{T}_{\text {viscous }}-\mathrm{T}_{\mathrm{l}}\right)=(1 / \mathrm{J})\left(\mathrm{L}_{\mathrm{af}} \mathrm{i}_{\mathrm{a}} \mathrm{i}_{\mathrm{f}}-\mathrm{B}_{\mathrm{m}} \omega_{\mathrm{r}}-\mathrm{T}_{\mathrm{l}}\right)$

Dynamics of rotor angular displacement $\left(\mathrm{d} \theta_{\mathrm{r}} / \mathrm{dt}\right) \omega_{\mathrm{r}}$

The derived three first order differential equations are rewritten in the s-domain

$\mathrm{i}_{\mathrm{a}}(\mathrm{s})=\frac{[-\operatorname{LafIf}(\mathrm{s}) \omega \mathrm{r}(\mathrm{s})+\mathrm{ua}(\mathrm{s})]}{[\mathrm{ra}+\mathrm{Las}]}$

$\omega_{\mathrm{r}}(\mathrm{s})=\left[\mathrm{L}_{\mathrm{af}} \mathrm{i}_{\mathrm{a}}(\mathrm{s}) \mathrm{i}_{\mathrm{f}}-\mathrm{T}_{1}\right] /\left[\mathrm{Js}+\mathrm{B}_{\mathrm{m}}\right]$

$\mathrm{i}_{\mathrm{f}}(\mathrm{s})=\left[\mathrm{u}_{\mathrm{f}}(\mathrm{s})\right] /\left[\mathrm{L}_{\mathrm{f}} \mathrm{s}+\mathrm{r}_{\mathrm{f}}\right]$

From Newton's second law, Torsional-Mechanical equation is given is given as $\mathrm{d} \omega_{\mathrm{r}} / \mathrm{dt}=(1 / \mathrm{J})\left(-\mathrm{T}_{\mathrm{e}}-\mathrm{T}_{\text {viscous }}+\mathrm{T}_{\mathrm{pm}}\right)=(1 / \mathrm{J})\left(-\mathrm{L}_{\mathrm{a}} \mathrm{i}_{\mathrm{a}} \mathrm{i}_{\mathrm{f}}-\mathrm{B}_{\mathrm{m}} \omega_{\mathrm{r}}+\mathrm{T}_{\mathrm{pm}}\right)$

The nonlinear differential equation for separately excited DC generator which is found using Kirchoff's Voltage Law

$\mathrm{di}_{\mathrm{a}} / \mathrm{dt}=-\left(\mathrm{r}_{\mathrm{a}} / \mathrm{L}_{\mathrm{a}}\right) \mathrm{i}_{\mathrm{a}}+\left(\mathrm{L}_{\mathrm{a}} / \mathrm{L}_{\mathrm{a}}\right) \mathrm{i}_{\mathrm{f}} \omega_{\mathrm{r}}-\left(1 / \mathrm{L}_{\mathrm{a}}\right) \mathrm{u}_{\mathrm{a}}$

$\mathrm{di}_{\mathrm{f}} / \mathrm{dt}=-\left(\mathrm{r}_{\mathrm{f}} / \mathrm{L}_{\mathrm{f}}\right) \mathrm{i}_{\mathrm{f}}+\left(1 / \mathrm{L}_{\mathrm{f}}\right) \mathrm{u}_{\mathrm{f}}$

$\mathrm{d} \omega_{\mathrm{r}} / \mathrm{dt}=-\left(\mathrm{L}_{\mathrm{a} f} / \mathrm{J}\right) \mathrm{i}_{\mathrm{a}} \mathrm{i}_{\mathrm{f}}-\left(\mathrm{B}_{\mathrm{m}} / \mathrm{J}\right) \omega_{\mathrm{r}}+\left(\mathrm{T}_{\mathrm{l}} / \mathrm{J}\right)$

The expression for the voltage at the load terminal must be used.

For the resistive load $\mathrm{R}_{1}$

$\mathrm{u}_{\mathrm{a}}=\mathrm{R}_{\mathrm{L}} \mathrm{i}_{\mathrm{a}}$

Analysis of equation (3) indicates that the angular velocity of the separately excited motor can be regulated by changing the applied voltage to the armature and field windings

$\omega_{\mathrm{r}}=\left(\mathrm{u}_{\mathrm{a}}-\mathrm{r}_{\mathrm{a}} \mathrm{i}_{\mathrm{a}}\right) /\left(\mathrm{L}_{\mathrm{af}} \mathrm{i}_{\mathrm{f}}\right)=\mathrm{u}_{\mathrm{a}} / \mathrm{L}_{\mathrm{af}} \mathrm{i}_{\mathrm{f}}-\left(\mathrm{r}_{\mathrm{a}} /\left(\mathrm{L}_{\mathrm{af}} \mathrm{i}_{\mathrm{f}}\right)^{2}\right) \mathrm{T}_{\mathrm{e}}$

The flux is a function of the field current in the stator windings and higher angular velocity can be achieved by field weakening by reducing the stator current.

However, there exists a mechanical limit imposed on the maximum angular velocity. The maximum allowed (rated) armature current is specified as well. One concludes that the electromagnetic torque is bounded.

$\mathrm{T}_{\mathrm{e}}=\mathrm{L}_{\mathrm{af}} \mathrm{i}_{\mathrm{f}} \mathrm{i}_{\mathrm{a}}$ 


\section{Structure of Fuzzy Logic}

\section{Fuzzy Logic Controller}

There are specific components characteristic of a fuzzy controller to support a design procedure. Figure 3 shows the controller between the pre-processing block and post processing block.

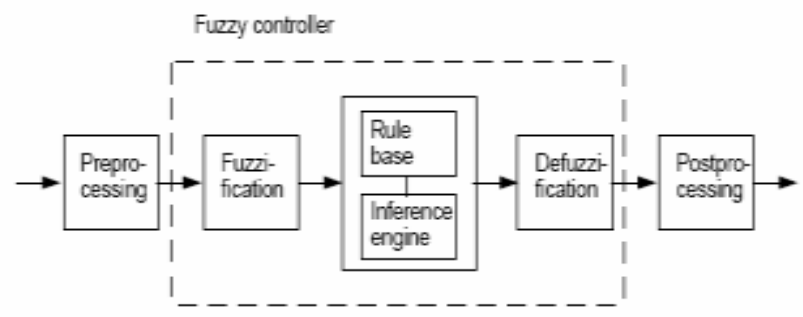

Figure 1: Structure of fuzzy logic controller

\section{Preprocessing}

The inputs are most often hard or crisp measurement from some measuring equipment rather than linguistic. A preprocessor, the first block in Figure 1 shows the conditions the measurements before enter the controller.

\section{Fuzzification}

The first block inside the controller is fuzzification which converts each piece of input data to degrees of membership by a lookup in one or several membership functions. The fuzzification block matches the input data with the conditions of the rules to determine. There is degree of membership for each linguistic term that applies to the input variable.

\section{Rule Base}

The collection of rules is called a rule base. The rules are in "If Then" format and formally the If side is called the conditions and the Then side is called the conclusion. The computer is able to execute the rules and compute a control signal depending on the measured inputs error (e) and change in error, $d(e)$. In a rule based controller the control strategy is stored in a more or less natural language. A rule base controller is easy to understand and easy to maintain for a non- specialist end user and an equivalent controller could be implemented using conventional techniques.

\section{Defuzzification}

Defuzzification is when all the actions that have been activated are combined and converted into a single non-fuzzy output signal which is the control signal of the system. The output levels are depending on the rules that the systems have and the positions depending on the non-linearity's existing to the systems. To achieve the result, develop the control curve of the system representing the I/O relation of the systems and based on the information; define the output degree of the membership function with the aim to minimize the effect of the non-linearity.

\section{Post processing} integrator.

The post processing block often contains an output gain that can be tuned and also become as an

\section{Rule Base For Speed Control Of De Motor}

The triangular membership functions for input variable speed error and control output i.e. change in PWM input are shown.

The general considerations in the design of the controller are:

1. If both error is zero, then maintain the present control setting i.e. output=0.

2. If the error is not zero but is approaching this value at a satisfactory rate, then maintain the present control setting.

3. If the error is growing then change the control signal output depending on the magnitude and sign of error to force the error towards zero. 


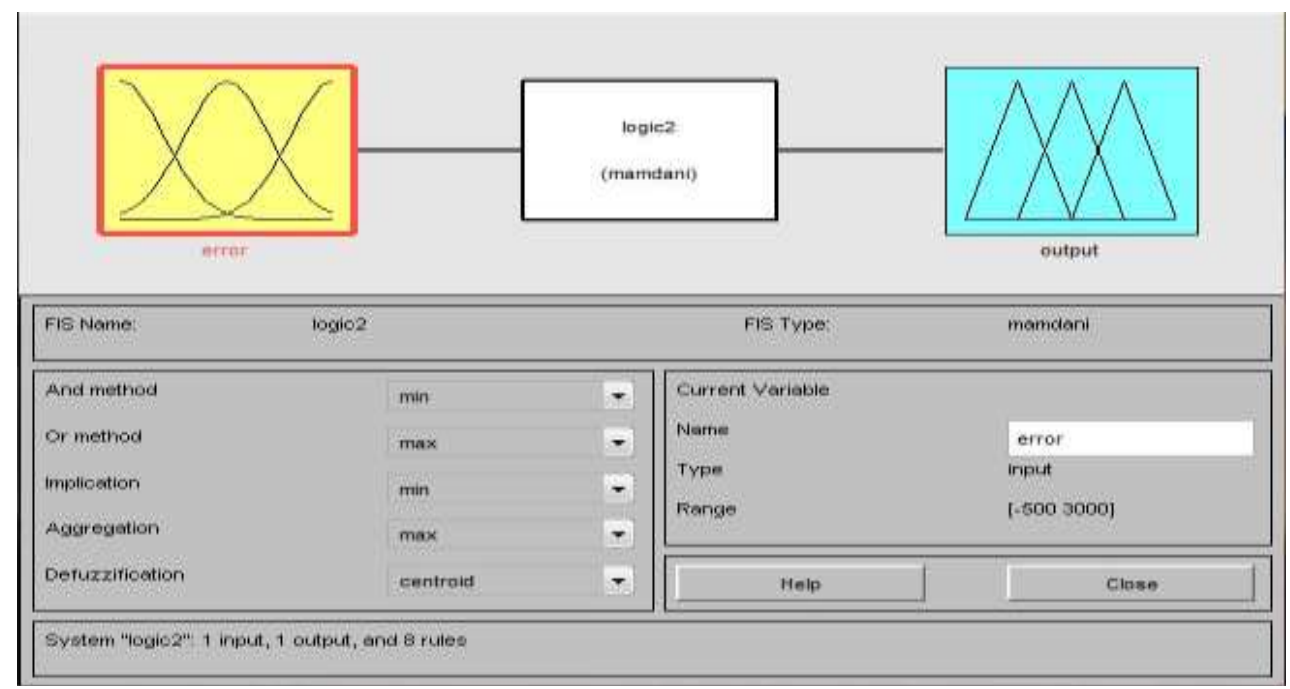

Figure 2: Membership functions

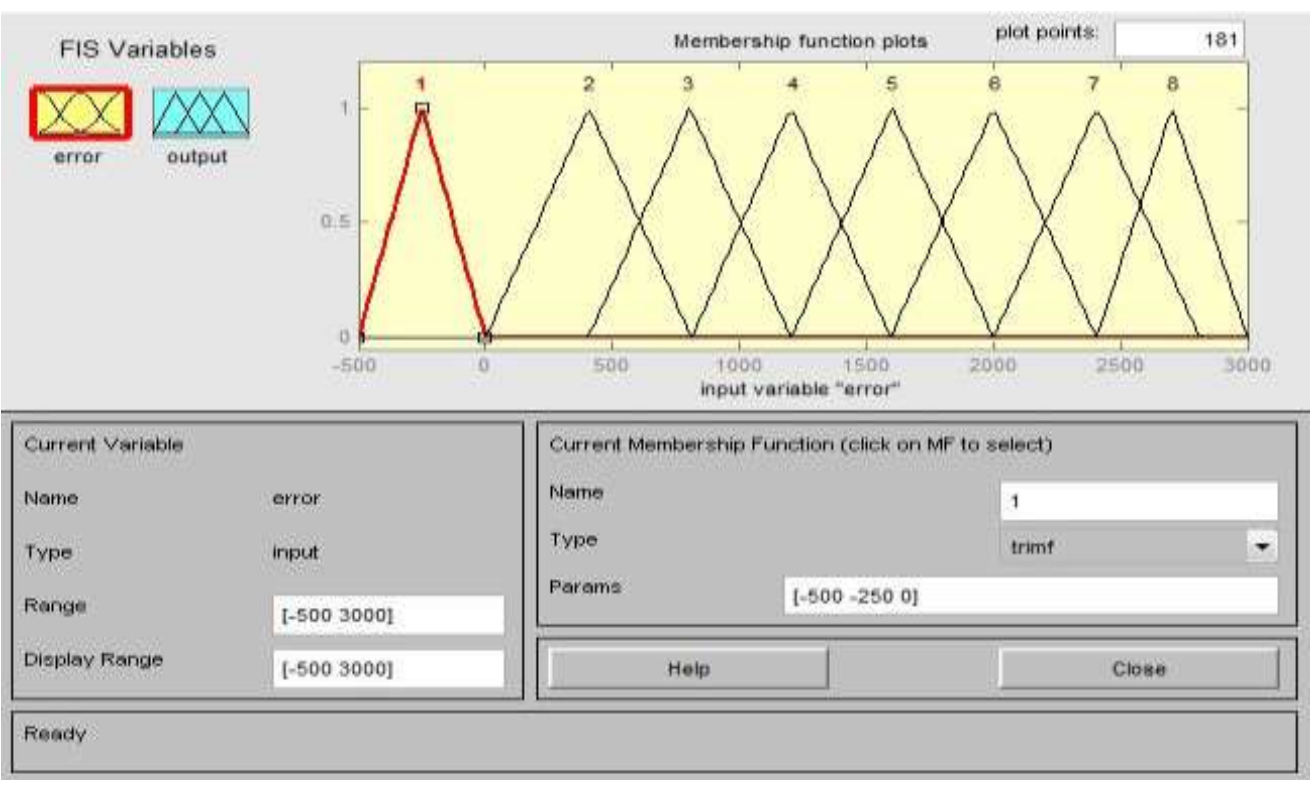

Figure 3: Error

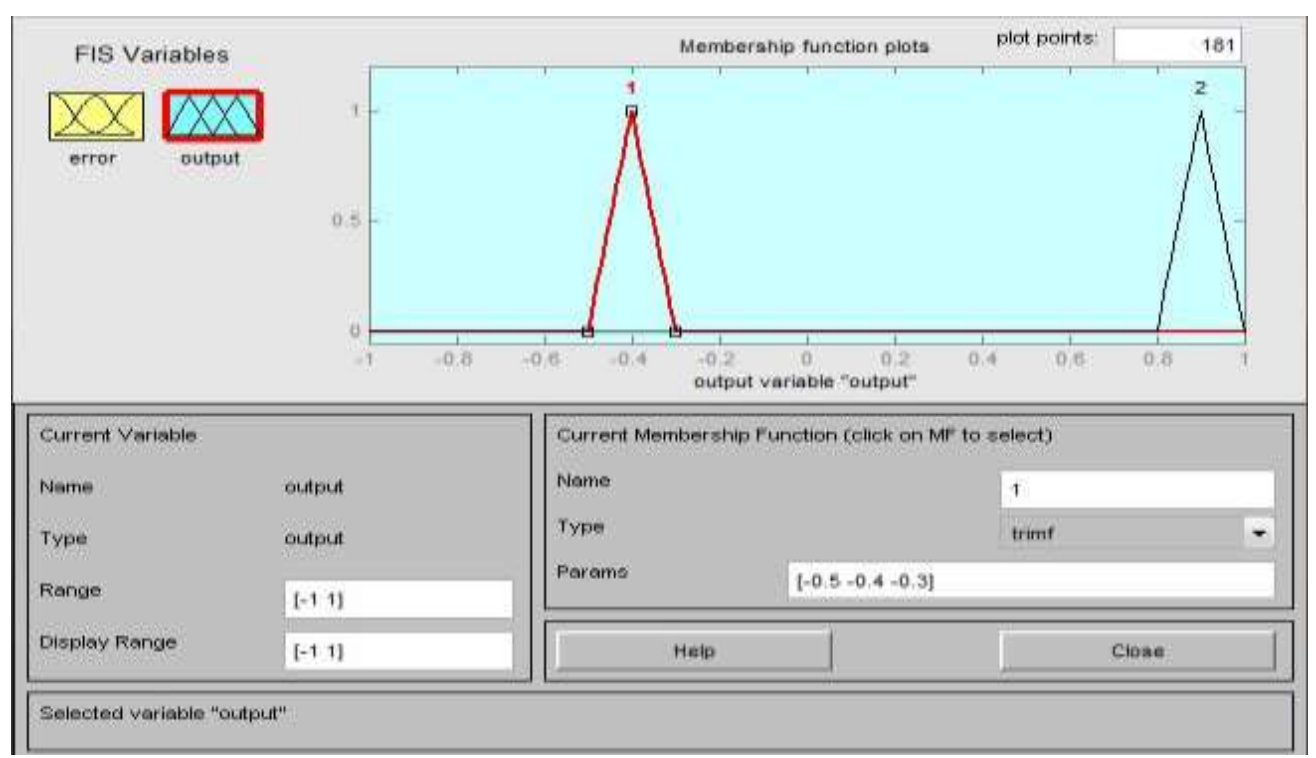

Figure 4: Output 


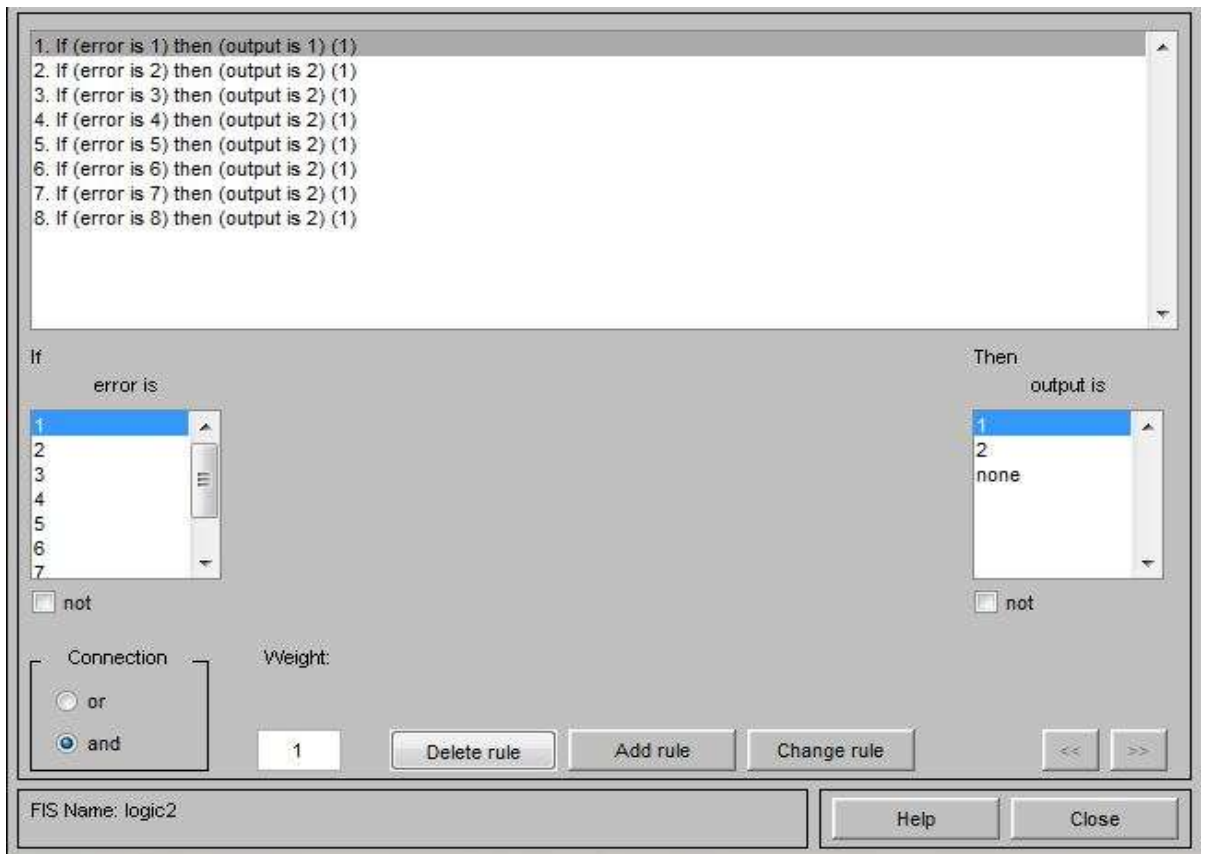

Figure 5: Rules

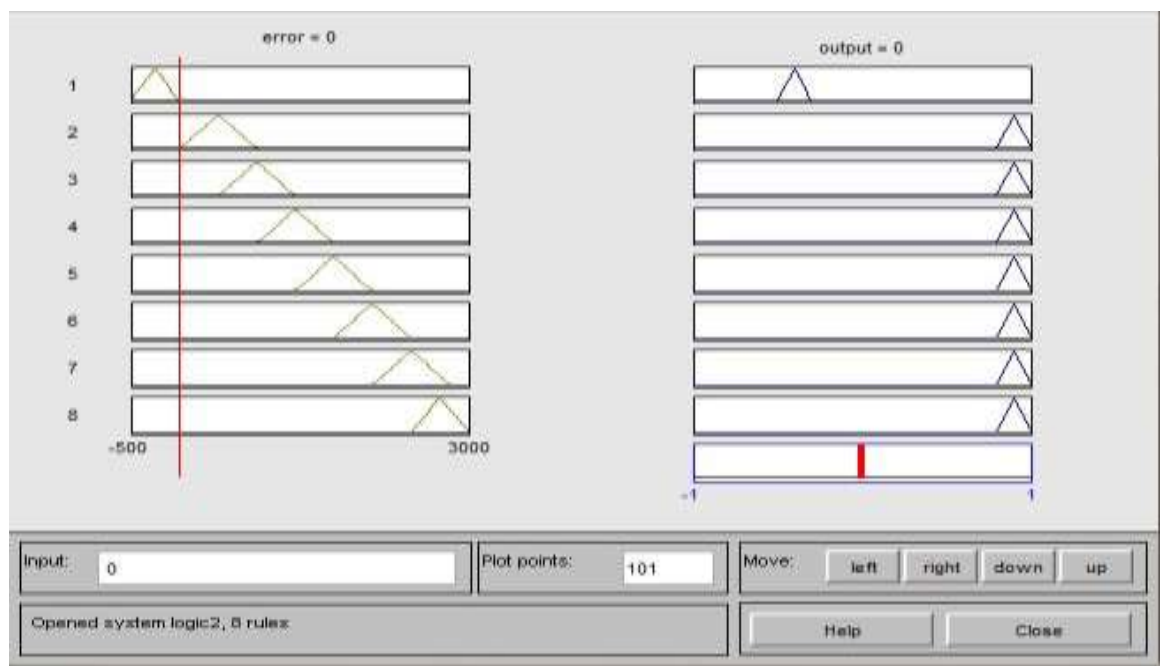

Figure 6: Rule Viewer

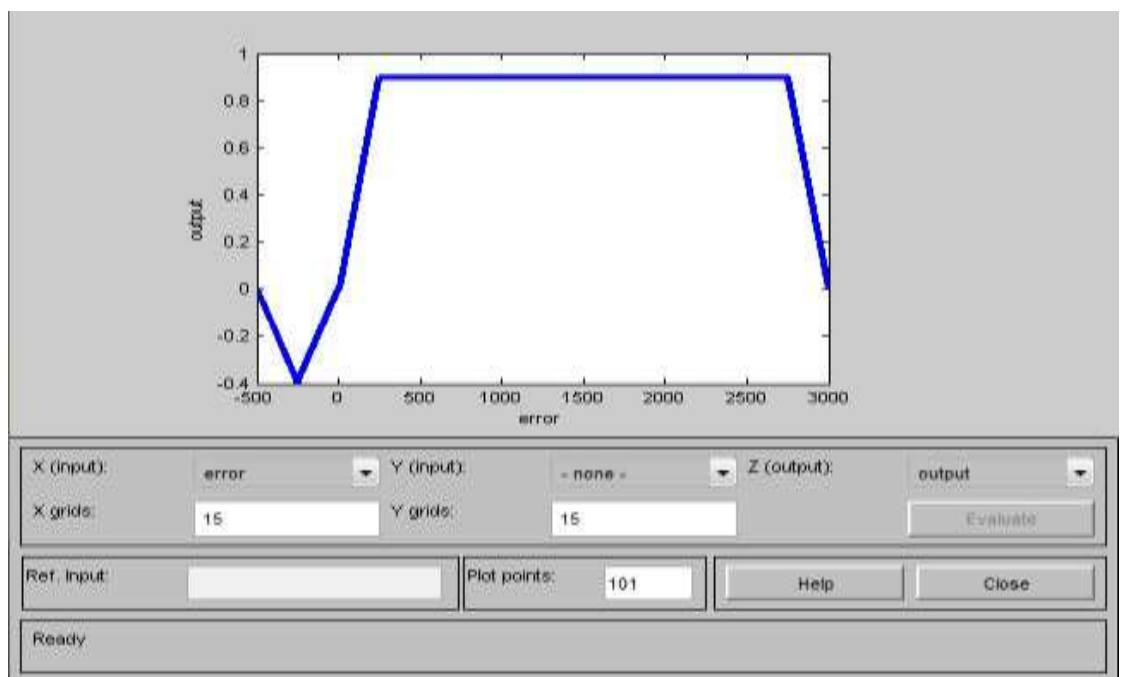

Figure 7: Surface Viewer 


\section{Specification of the separately excited dc motor}

Armature resistance $\left(\mathrm{R}_{\mathrm{a}}\right)=0.6 \Omega$

Armature inductance $\left(\mathrm{L}_{\mathrm{a}}\right)=0.012 \mathrm{H}$

Mechanical inertia $\left(\mathrm{J}_{\mathrm{m}}\right)=0.15 \mathrm{Kg} \cdot \mathrm{m}^{2}$

Friction coefficient $(\mathrm{B})=0.008 \mathrm{~N} \cdot \mathrm{m} / \mathrm{rad} / \mathrm{s}$

Back emf constant $(\mathrm{K})=1.8 \mathrm{~V} / \mathrm{rad} / \mathrm{s}$

Rated speed $=2100 \mathrm{rpm}$

At time $\mathrm{t}=0.01 \mathrm{sec}$ we have taken an external load torque $20 \mathrm{~N} . \mathrm{m}$

\section{Result}

In order to validate the control strategies as described above, digital simulation were carried out on a converter dc motor drive system whose parameters are mentioned.

The MATLAB/SIMULINK model of system under study with fuzzy controller is shown in Figure 8. The speed of separately excited dc motor has been successfully controlled by using fuzzy logic controller technique.

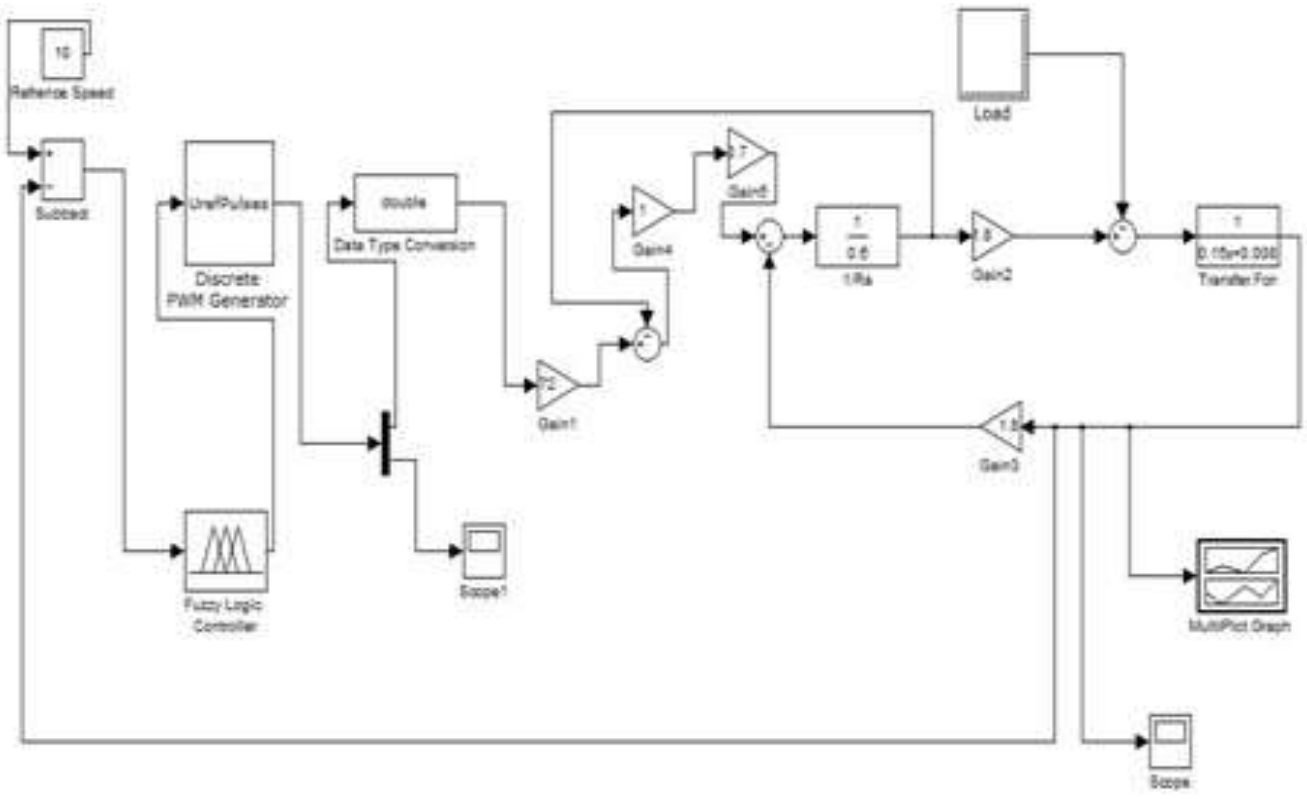

Figure 8: Simulink Model

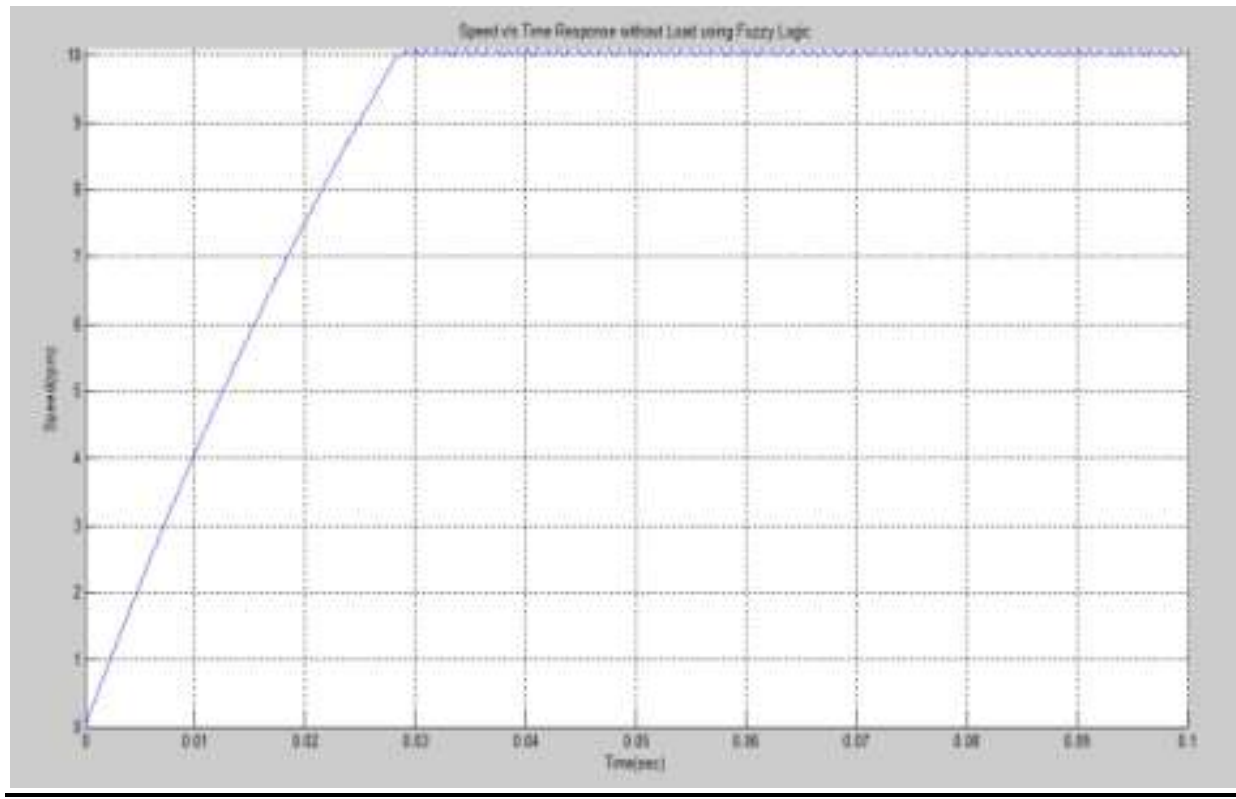

Figure 9: Without Load 


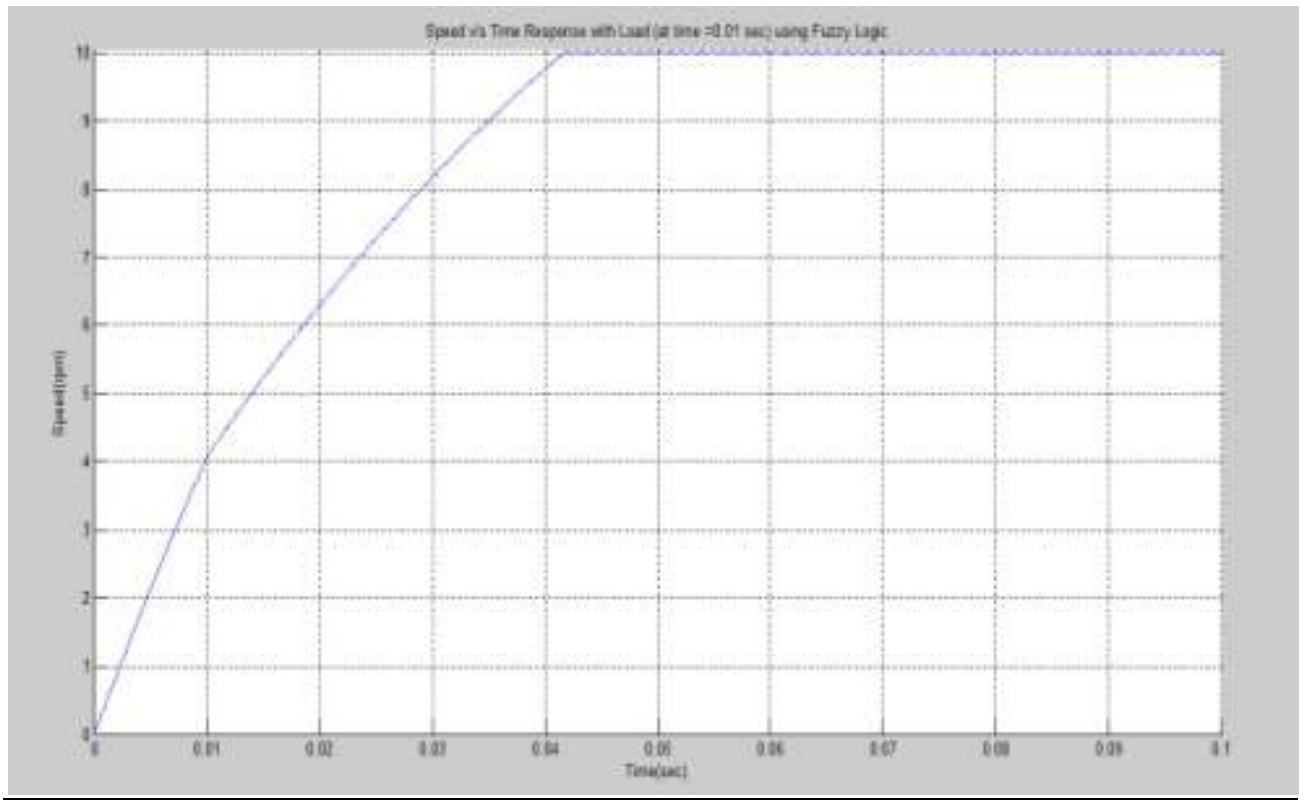

Figure 10: With Load (at time $=0.01 \mathrm{sec}$ )

\section{References}

[1] FUZZY AND SOFT COMPUTING- Jyh-shing, Roger Jang, Chuen-Tsai Sun

[2] K. B. Mohanty, “Fuzzy remote controller for converter DC motor drives", Parintantra, Vol. 9, No. 1, June 2004

[3] Zimmermann, H. (2001). Fuzzy Set Theory And Its Applications. Boston: Kluwer Academic Publishers. ISBN 0-7923-7435-5

[4] Yager, Ronald R, Filev, Dimitar P. (1994). Essentials of Fuzzy Modelling and Control. New York: Wiley. ISBN 0-471-01761-2

[5] Santos, Eugene S. (1970). "Fuzzy Algorithms". Information and Control 17 (4)

[6] B.C Kuo-Digital Control Systems-2 ${ }^{\text {nd }}$ Edition 